\title{
Dual-parameter control of the pole frequency in case of universal filter with MCDU elements
}

JEŘÁBEK, J.; ŠOTNER, R.; HERENCSÁR, N.; POLÁK, J.; DVOŘÁK, J.; KOTON, J.

Analog Integrated Circuits and Signal Processing

2017, vol. 89, iss. 3, pp. 705-718

ISSN (Print): 0925-1030

ISSN (Online): 1573-1979

DOl: http://dx.doi.org/10.1007/s10470-016-0756-7

Accepted manuscript 


\title{
Dual-Parameter Control of the Pole Frequency In Case of Universal Filter with MCDU Elements
}

\author{
Jan Jerabek $^{1}$, Roman Sotner ${ }^{2}$, Norbert Herencsar ${ }^{1}$, Josef Polak ${ }^{1}$, Jan Dvorak ${ }^{1}$, Jaroslav Koton ${ }^{1}$ \\ ${ }^{1}$ Brno University of Technology, Dept. of Telecommunications, Technicka 12, 61600 Brno, Czech Republic \\ jerabekj@feec.vutbr.cz, herencsn@feec.vutbr.cz,xpolak24@stud.feec.vutbr.cz, xdvora0s@stud.feec.vutbr.cz, \\ koton@feec.vutbr.cz \\ ${ }^{2}$ Brno University of Technology, Dept. of Radio Electronics, Technicka 12, 61600 Brno, Czech Republic \\ sotner@feec.vutbr.cz
}

\begin{abstract}
This paper presents an universal filter with control of the pole frequency by two mutually independent parameters - current gain $(B)$ and intrinsic resistance $\left(R_{\mathrm{X}}\right)$ in frame of two MCDU active elements. This type of control extend and also improve features of the tuning range and is referred to as dual-parameter control. The current-mode filter is of the second order and the required type of the response (low pass, inverting band pass, high pass, band reject and all pass) is obtained by proper selection/combination of input(s) - this filter is of the multiple-input single-output type (MISO). The filter employs two capacitors, two modified current differencing units (MCDUs), each of them with four controllable parameters and one multiple-output current follower (MO$\mathrm{CF}$ ). The paper includes tuning range analysis, the simulation results with behavioral models and also laboratory measurement results with the same models. Moreover, designed transistor-level structures of both the active elements proposed in ON Semi I3T CMOS 0.35 um technology that were used for final simulations confirming the workability and features of the designed concept.
\end{abstract}

Keywords: Current differencing unit, dual-parameter control, electronic control, MCDU, universal filter.

\section{Introduction}

Possibility of change or adjusting of an analogue circuit (filter, oscillator, generator, etc.) is always a very important requirement in the signal processing area. Filtering of a part of the frequency spectrum of the signal is a basic operation of suppressing or amplifying of some spectral components or the parts of processed bandwidth [1]. Many scientific works [2-7] focus on filters referred to as multifunction or universal. These filters have several transfer functions available between different nodes of the network. These circuits are referred to as a triple input - single output (TISO) or single input - triple output (SITO), or more generally as a single input multiple output (SIMO) [8] or a multiple input - single output (MISO) [9]. The most general form is multiple input multiple output (MIMO) [10] type, usually with many input or output terminals. When a filter is universal [11-12], each of five standard transfer functions (low pass, high pass, band pass, band reject and all pass) is available from the same topology by proper selection of input, output or by reconfiguration in case of reconfigurable filters [13-14]. A filter is adjustable or tunable if one or more of its parameters (angular frequency, quality factor, bandwidth, pass-band or stop-band gain) are controllable and their control must be mutually independent [15-17]. Controllability of the filter can be achieved by driving of one or more parameters 
of active element (transconductance $g_{\mathrm{m}}[18,19]$, intrinsic resistance $R_{\mathrm{X}}$ [20], current gain [21-22] or voltage gain [23]), most frequently controlled by DC voltage or DC current. Table 1 summarizes some of the previous works that focus on current-mode universal $2^{\text {nd }}$-order filters providing some type of electronic control.

As is obvious from Table 1, the previous filtering solutions vary in the type of filter topology and the number of active elements being used, in necessity of discrete resistors in the structure and in controllability testing. As we can see from Table 1, typical count of active elements required in MISO topology of the filter is three [8], [24], [25], [26], [27]. There are simpler solutions ([9], [28], [29], [30] for example) where two active elements are sufficient to establish basic universal filtering transfer responses. However, their electronic controllability is very limited in many cases [28]. We can distinguish several approaches to control useful features of the filter.

Simple active devices usually offer single active parameter ( $g_{\mathrm{m}}$ or $R_{\mathrm{x}}$ in many cases) ensuring electronic controllability of target features of the filter (always pole frequency). However, for linear control of the pole frequency and quality factor adjusting, several active devices must be used [24], [28], [29], [31], [32]. Unfortunately, the simplest solutions allow only pole frequency control [28], [29]. The improved features of the resulting circuit are obtained if possibility of dual parameter control in frame of single active device is available [9], [25], [26], [27], [30], [33], [34], [35]. It helps to ensure independent control of quality factor and/or passband gain adjusting [25]. Unfortunately, it is valid only for limited number of transfer responses. On the other hand, some really simple solutions (one active device including two controllable parameters) in filtering structure are also suitable for construction of universal filters [33], [34], [35]. However, controllability of other features than pole frequency is restricted in many cases and extension of tunability range is not allowed. Especially SIMO CM structures (for example [28]) have a problem with output responses flowing through grounded passive elements (capacitors in most cases) that complicate mirroring of the response out of the filtering structure (real serial input resistance to working capacitor), see for example [36], [37]. 
Table 1. Several examples of current-mode universal $2^{\text {nd }}$-order filters with electronic control

\begin{tabular}{|c|c|c|c|c|c|c|c|c|c|c|}
\hline 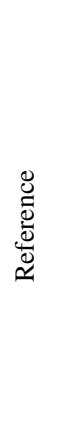 & 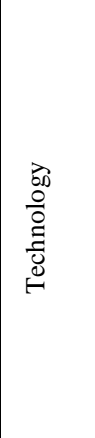 & 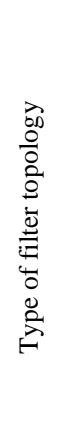 & 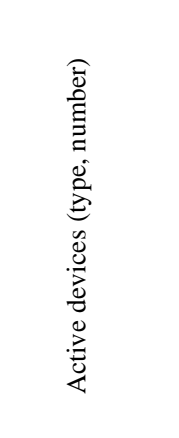 & 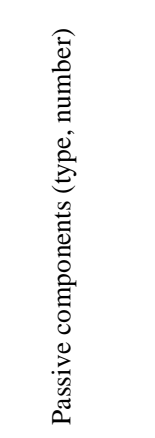 & 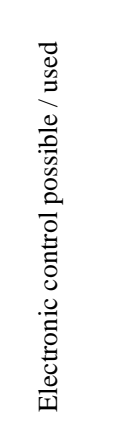 & 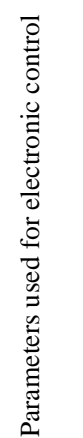 & 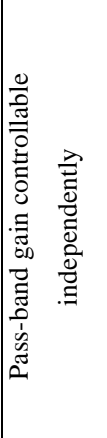 & 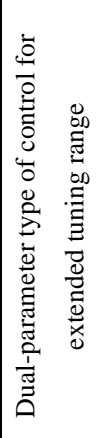 & 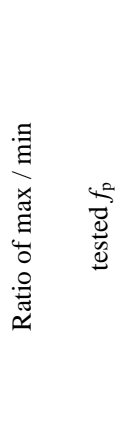 & 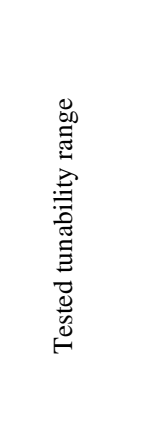 \\
\hline [8] & CMOS & SITO & UCC (3) & $\mathrm{C}(2), \mathrm{R}(2)$ & Yes / No & $\mathrm{N} / \mathrm{A}$ & No & No & N/A & N/A \\
\hline [9] & CMOS & MISO & CСССТА (2) & $\mathrm{C}(2)$ & Yes / Yes & $g_{\mathrm{m}}, R_{\mathrm{x}}$ & No & No & N/A & Not clear \\
\hline [24] & CMOS & TITO & DO-CCCII (3) & $\mathrm{C}(2)$ & Yes / No & N/A & No & No & N/A & N/A \\
\hline$[25]$ & BJT & SIMO & CCCCTA (3) & $\mathrm{C}(2)$ & Yes / Yes & $g_{\mathrm{m}}, R_{\mathrm{x}}$ & $\begin{array}{l}\text { Yes/ } \\
\text { BP }\end{array}$ & Yes & 4.3 & $\begin{array}{c}1.75-7.52 \\
\mathrm{MHz}\end{array}$ \\
\hline$[26]$ & BJT & MISO & CCCDTA (3) & $\mathrm{C}(2)$ & Yes / Yes & $g_{\mathrm{m}}, R_{\mathrm{x}}$ & No & No & 8.3 & $\begin{array}{c}119-991 \\
\mathrm{kHz}\end{array}$ \\
\hline$[27]$ & BJT & SIMO & CCCII (3) & $\mathrm{C}(2)$ & Yes / Yes & $R_{\mathrm{x}}, B$ & No & No & N/A & Not clear \\
\hline$[28]$ & CMOS & SIMO & CFTA (2) & C (2), R (1) & Yes / No & N/A & No & No & N/A & Not clear \\
\hline [29] & BJT & MISO & CCCII (2) & C (2) & Yes / Yes & $R_{\mathrm{x}}$ & No & No & 20 & $\begin{array}{c}0.1-2 \\
\mathrm{MHz}\end{array}$ \\
\hline$[30]$ & CMOS & MISO & CCCCTA (2) & $\mathrm{C}(2)$ & Yes/Yes & $g_{\mathrm{m}}, R_{\mathrm{x}}$ & No & No & N/A & Not clear \\
\hline [31] & BJT & MISO & CCCII (4) & C (2), R (2) & Yes / Yes & $R_{\mathrm{x}}$ & No & No & 4.4 & $\begin{array}{c}2.76-12.25 \\
\mathrm{MHz}\end{array}$ \\
\hline$[32]$ & CMOS & SIMO & $\begin{array}{c}\text { CCCFTA (3), } \\
\text { OTA }(1)\end{array}$ & $\mathrm{C}(2)$ & Yes / Yes & $g_{\mathrm{m}}$ & No & No & 71 & $\begin{array}{c}0.048-3.4 \\
\mathrm{MHz}\end{array}$ \\
\hline [33] & CMOS & MISO & CFTA (1) & $\mathrm{C}(2), \mathrm{R}(1)$ & Yes / Yes & $\overline{g_{\mathrm{m}}, R_{\mathrm{x}}}$ & No & No & N/A & Not clear \\
\hline$[34]$ & BJT & MISO & CCCDTA (1) & $\mathrm{C}(2)$ & Yes / Yes & $g_{\mathrm{m}}, R_{\mathrm{x}}$ & No & No & N/A & Not clear \\
\hline$[35]$ & BJT & MISO & CCCFTA (1) & $\mathrm{C}(2)$ & Yes/Yes & $g_{\mathrm{m}}, R_{\mathrm{x}}$ & No & No & N/A & Not clear \\
\hline Fig. 3 & CMOS & MISO & $\begin{array}{l}\text { MCDU (2), } \\
\text { MO-CF (1) }\end{array}$ & C (2) & Yes / Yes & $R_{\mathrm{x}}, B$ & $\begin{array}{c}\text { Yes/ } \\
\text { HP, BP }\end{array}$ & Yes & 140 & $\begin{array}{c}0.04-5.6 \\
\mathrm{MHz}\end{array}$ \\
\hline
\end{tabular}

Notes:

UCC - universal current conveyor, CCCCTA - current controlled current conveyor transconductance amplifier, DO-CCCII - dual output current controlled current conveyor of second generation, CFTA - current follower transconductance amplifier, CCCDTA - current controlled current differencing transconductance amplifier, CCCII - current controlled current conveyor of second generation, OTA operational transconductance amplifier, CCCFTA - current controlled current follower transconductance amplifier, MCDU - modified current differencing unit, $\mathrm{MO}-\mathrm{CF}$ - multiple output current follower 
The target feature of our proposed structure is the widest pole-frequency tunability range. A short overview of the solutions briefly listed in Tab. 1 and further works (cited in references of discussed literature) indicate that this feature was not studied very often in the past. It is clear that multi-parameter control in frame of the active device is a key feature to obtain wideband tunability. To the best of authors' knowledge, except ref. [25], there have not been performed detailed studies regarding extension of adjustability of some parameters of the filter. Ref. [25] notes possibility of quality factor of the BP response enhancing by dual parameter control. BP response available in structure presented in [25] can be adjusted in pass-band by additional electronically controllable parameter. Moreover, control of pass-band gain can be obtained in some of so-called reconfigurable biquads (reconnection-less electronical reconfiguration of the transfer function between several responses) [38], however, they still do not solve extension of pole frequency tunability range. It always means additional adjustable active device in the loop. Therefore, we focused our effort on proposal of solution with enhanced range of pole frequency adjusting and without additional active device in the structure. It is allowed by utilization of quite new modification of current differencing unit [39], [40], where two independent current gains $(B)$ and two independent input resistances $\left(R_{\mathrm{x}}\right)$ are available and electronically controllable. A presented application of MCDU in this filtering structure seems to be really complex but CMOS solution simplifies it. We can see that the feature of dual parameter control is not based on simple adding of the current amplifier (gain) to specific position in the loop. The presented features of the filter are mostly given also by the existence of the second parameter in the integrator (input resistance of the current input $-R_{\mathrm{p}}, R_{\mathrm{n}}$ ). In other words, integrators based on MCDU have intentionally available feature of dual parameter control that is really beneficial in specific applications as we introduced here. Filtering structure presented in this paper offers also pass-band gain control in case of one of the BP responses and - as already mentioned - dual-parameter control of pole frequency (not only central frequency of the BP) that brings several times higher range of adjusting. Pole frequency $\left(f_{\mathrm{P}}\right)$ is controlled by both the current gain and intrinsic resistance. Moreover, several transfer functions of our filtering circuit have independently controllable pass-band gain. Note that this feature is not available in any of te listed hitherto published solutions.

This paper is divided as follows: Introductory section discusses the limited features (tunability range) of current state-of-the-art (electronically tunable filters) and compares already known approaches. Then both simulations and measurements with behavioral models of the MCDUs follow as well as simulations with proposed MCDU CMOS solution in $0.35 \mu \mathrm{m}$ CMOS technology.

\section{Designed Universal Filter}

Designed filter contains two Modified Current Differencing Units (MCDUs) [40] and one simple MultipleOutput Current Follower [16].

MCDU element (Fig. 1) is described by the following equations:

$$
\begin{gathered}
I_{+x}=I_{p} B_{1}-I_{n} B_{2}, \\
V_{p}=V_{Y 1}+R_{p} I_{p}, \\
V_{n}=V_{Y 2}+R_{n} I_{n},
\end{gathered}
$$


where $I_{+\mathrm{x}}$ represents output current, $I_{\mathrm{p}}$ represents current flowing into positive input, $I_{\mathrm{n}}$ represents current flowing into negative input, $B_{1}$ is voltage-controlled current gain in positive path, $B_{2}$ is voltage-controlled current gain in negative path, $Y_{1}$ and $Y_{2}$ are auxiliary voltage terminals, $R_{\mathrm{p}}$ is voltage-controlled intrinsic resistance of $p$ input and $R_{\mathrm{n}}$ is voltage-controlled intrinsic resistance of $n$ input.

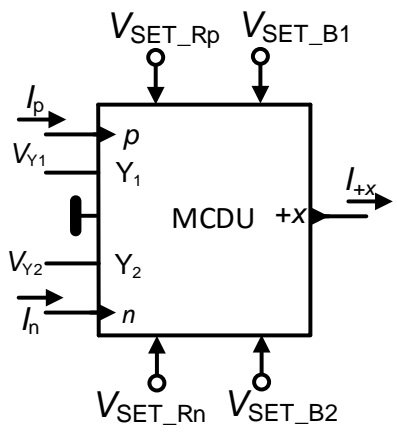

Fig. 1. Schematic symbol of Modified Current Differencing Unit (MCDU) active element.

MO-CF element is very simple and input current is only mirrored or inverted to respective output according to the symbol or current arrow used on output side of the circuit. It is very useful that MO-CF can be easily implemented by multiple-output current conveyor of second generation with grounded Y terminal(s), in our particular case by Universal Current Conveyor (UCC) [8] (Fig. 2).

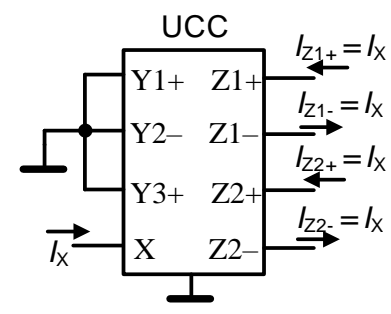

Fig. 2. Schematic symbol of Multiple-Output Current Follower (MO-CF) active element implemented by Universal Current Conveyor (UCC).

The whole filtering structure including four input nodes and one output terminal is shown in Fig. 3 [42].

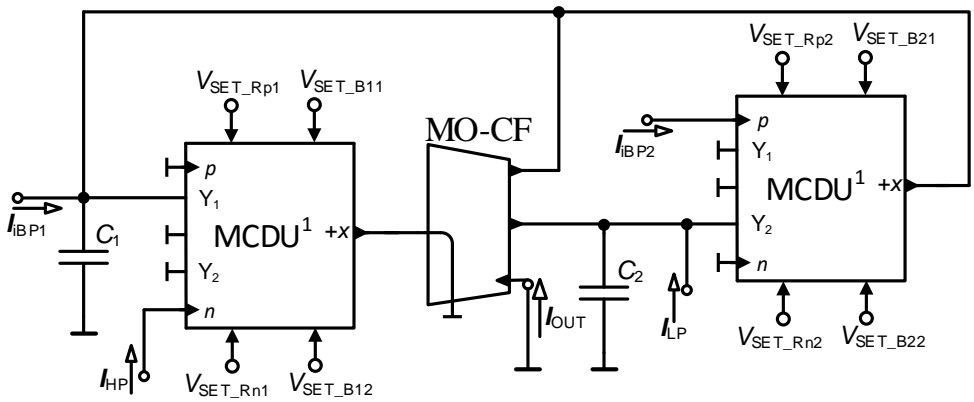

Fig. 3. Designed current-mode universal filter with the dual-parameter control of the $f_{\mathrm{P}}$ 
All transfer functions of this filter are (LP = low pass, $\mathrm{iBP}=$ inverted band pass, $\mathrm{HP}=$ high pass):

$$
\begin{gathered}
K_{H P}(\boldsymbol{s})=\frac{\boldsymbol{I}_{O U T}}{\boldsymbol{I}_{H P}}=\frac{\boldsymbol{s}^{2} C_{1} C_{2} B_{12}}{D(\boldsymbol{s})}, \\
K_{i B P 1}(\boldsymbol{s})=\frac{\boldsymbol{I}_{O U T}}{\boldsymbol{I}_{i B P 1}}=-\frac{\boldsymbol{s} C_{2} G_{p 1} B_{11}}{D(\boldsymbol{s})}, \\
K_{i B P 2}(\boldsymbol{s})=\frac{\boldsymbol{I}_{O U T}}{\boldsymbol{I}_{i B P 2}}=-\frac{\boldsymbol{s} C_{2} G_{p 1} B_{11} B_{21}}{D(s)}, \\
K_{L P}(\boldsymbol{s})=\frac{\boldsymbol{I}_{O U T}}{\boldsymbol{I}_{L P}}=\frac{G_{p 1} G_{n 2} B_{11} B_{22}}{D(s)},
\end{gathered}
$$

where denominator is the same for all of the transfer functions:

$$
D(s)=s^{2} C_{1} C_{2}+s C_{2} G_{p 1} B_{11}+G_{p 1} G_{n 2} B_{11} B_{22}
$$

The meaning of symbols is obvious from Fig. 3 and the previous text, $G_{\mathrm{p} 1}=1 / R_{\mathrm{p} 1}, G_{\mathrm{n} 2}=1 / R_{\mathrm{n} 2}$. When excitation represented by $I_{\mathrm{HP}}$ and $I_{\mathrm{LP}}$ currents is available simultaneously, band reject (BR) function is obtained. If also $I_{\mathrm{iBP} 1}$ is available, all-pass (AP) response with unity gain is obtained on the output terminal. Note that iBP1 and $\mathrm{iBP} 2$ transfer functions require inversion of input current in order to provide inverting version of $\mathrm{BP}$ function, however, it is important only for AP response. Therefore, if AP response is not necessary, inversion of input current is also not necessary in particular application.

Angular frequency $\left(\omega_{0}\right)$ and quality factor $(Q)$ are equal to:

$$
\begin{gathered}
\omega_{0}=\sqrt{\frac{G_{p 1} G_{n 2} B_{11} B_{22}}{C_{1} C_{2}}}, \\
Q=\sqrt{\frac{C_{1} G_{n 2} B_{22}}{C_{2} G_{p 1} B_{11}}} .
\end{gathered}
$$

From eqs. (9) and (10) can be derived that if $G_{\mathrm{p} 1}=G_{\mathrm{n} 2}=G=1 / R$ is controlled, $\omega_{0}$ is adjusted without disturbing $Q$. Let us assume that this is the first tuning parameter in the following text. Same is valid for $B_{11}=$ $B_{22}=B$ (the second tuning parameter in the following text). Therefore, there are two ways how to control $\omega_{0}$ that can be used mutually independently or even better can be combined in order to obtain extended control range as will be shown later in this paper. Note that $B_{12}$ can be used to adjust independently the pass-band gain of HP response and $B_{21}$ can independently control the pass-band gain of iBP2 transfer function. 


\section{Tuning Suitability Analyses}

Since no on-chip implementation of MCDU was initially available, one MCDU elements have to be behaviorally emulated by structure consisting of commercially available ICs [41], 6 pieces of EL2082 [40, 41] and one OPA860 $[40,41]$ and several passive components. MO-CF can be emulated by UCC-N1B_0520 model [8]. Of course this type of behavioral modelling has several drawbacks (usually limited bandwidth or dynamic range, or both) but it is very useful in preliminary phase of testing of application possibilities of the new circuits. This particular solution limits theoretically the first and second control voltages ( $\left.V_{\text {SET_R }}, V_{\text {SET_B }}\right)$ approximately from $0.05 \mathrm{~V}$ up to approximately $2.8 \mathrm{~V}$ and therefore also the tuning range of $R$ and $B$ is limited from the beginning. Usually, when tuning range is too wide (more than two decades, for instance), the problems with linearity, accuracy, bandwidth or transfer function shape occur in lower and/or upper corner of tuning range. Therefore, we conducted several tuning suitability analyses of the first and second adjustable parameter ( $R$ and $B$ ) in order to find out applicable parameter range required for the widest possible tuning range of the $f_{\mathrm{P}}$ of the whole filter in our particular case. The initial parameters of the filter were chosen as follows: $R=\{9240 ; 188\} \Omega$ obtained by $V_{\text {SET_R }}=\{0.048 ; 2.75\} \mathrm{V}, B=\{0.05 ; 2.5\}$ obtained by $V_{\text {SET_B }}=\{0.048 ; 2.75\} \mathrm{V}$, capacitors $C_{1}=120$ $\mathrm{pF}$ and $C_{2}=240 \mathrm{pF}, Q=0.707$ (Butterworth approximation), $B_{12}=1, B_{21}=1$, leading theoretically to $f_{\mathrm{P}_{-} \text {THEOR }}=$ $\{0.005 ; 12.5\}$ MHz. This means that ratio between the highest and the lowest $f_{\mathrm{P}}$ is calculated as 2500 .

Series of graphs introduced below, include theoretical $f_{\mathrm{P}}$, simulated $f_{\mathrm{P}}$, (in case of $\mathrm{BR}$ response and when filter simulation was converging in PSpice) and relative error (\%) between these two values vs. tuning of first or second tuning parameters in several scenarios. Since one of tuning parameters was fixed in these cases, it represents single-parameter tuning procedure.

The first graph (Fig. 4) shows that if one tuning voltage has relatively low value $\left(V_{\text {SET}_{-} \mathrm{R}}=0.147 \mathrm{~V}\right.$, i.e. $R=$ $3060 \Omega$ ), filter will work only if second tuning voltage is not relative low (in this particular case works up from $V_{\text {SET_B }}=0.147 \mathrm{~V}$, i.e. $B=0.15$ ). The second graph (Fig. 5) presents inverse situation, when $V_{\text {SET_R }}=1.55 \mathrm{~V}$, i.e. $R=312 \Omega$, filter was working only up to $V_{\text {SET_B }}=1.55 \mathrm{~V}$, i.e. $B=1.5$. Fig. 6 and Fig. 7 show reciprocal situation $-V_{\text {SET_R }}$ is tuned while $V_{\text {SET_B }}$ is kept constant. Note that these results prove the same trend - if one control voltage is low, second cannot be relatively low and vice versa in order to keep the filter working in simulations.

In this case, the ratio between the highest and the lowest $f_{\mathrm{P}}$ is only 50 in theory, $f_{\mathrm{P}_{\mathrm{P}} \text { THEOR }}=\{0.15 ; 7.5\} \mathrm{MHz}$, however is not better than 30 in simulations, tuning range $f_{\mathrm{P}_{-} \mathrm{SIM}}=\{0.14 ; 4.2\} \mathrm{MHz}$ for instance (the best case). Therefore, it is obvious that single-parameter control actually limits the tuning range in this particular case. 


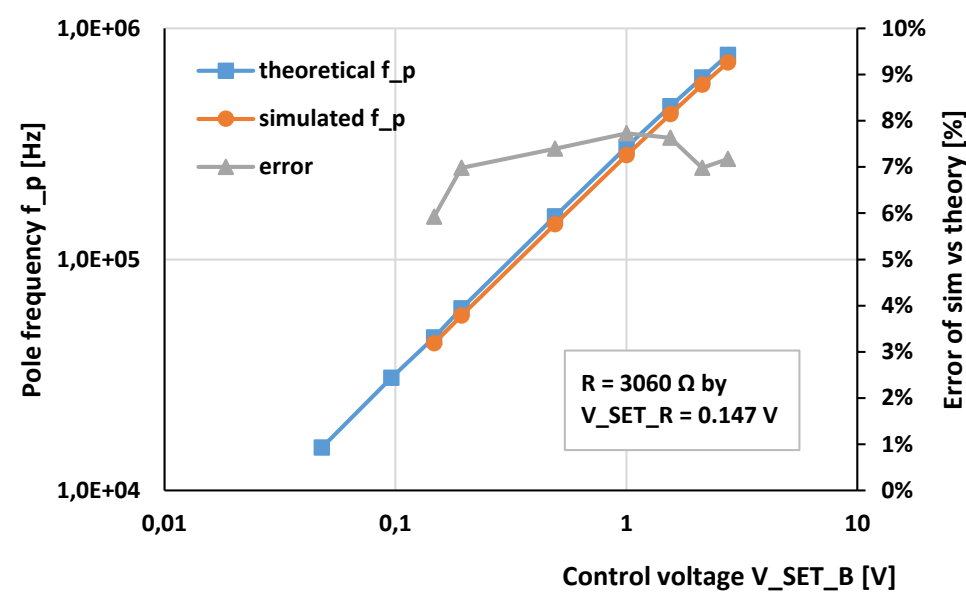

Fig. 4. Tuning suitability analysis under first set of conditions showing the possible workability of the filter (tuning of $V_{\text {SET_B }}$ while $V_{\text {SET_R }}$ is fixed to low value).

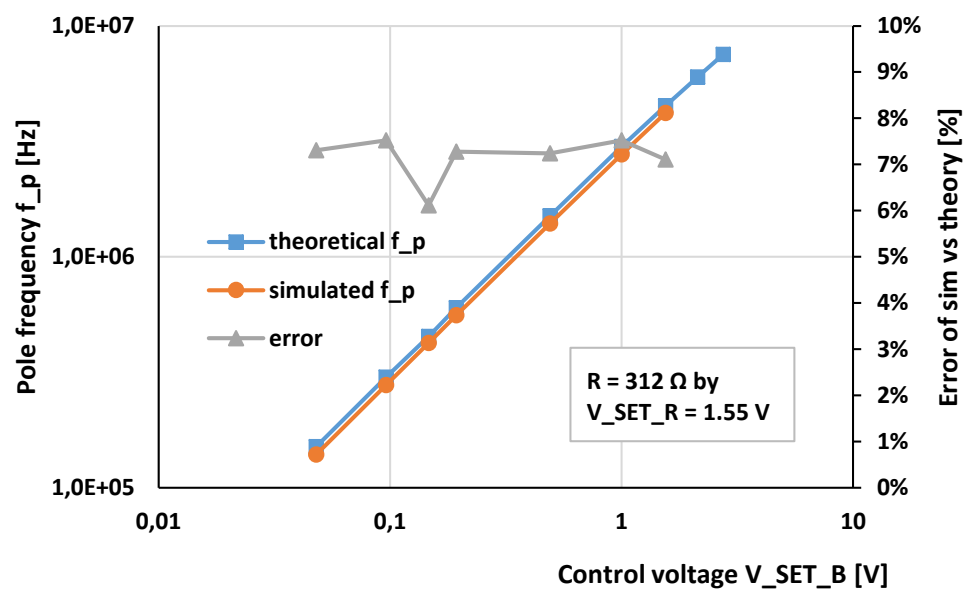

Fig. 5. Tuning suitability analysis under second set of conditions showing the possible workability of the filter (tuning of $V_{\text {SET_B }}$ while $V_{\text {SET_R }}$ is fixed to high value).

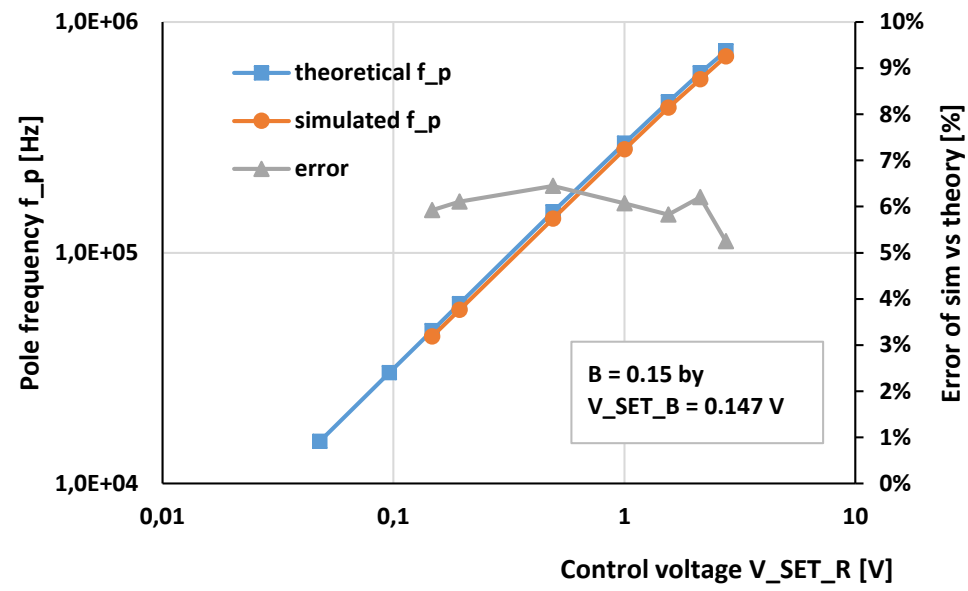

Fig. 6. Tuning suitability analysis under third set of conditions showing the possible workability of the filter (tuning of $V_{\text {SET_R }}$ while $V_{\text {SET_B }}$ is fixed to low value). 


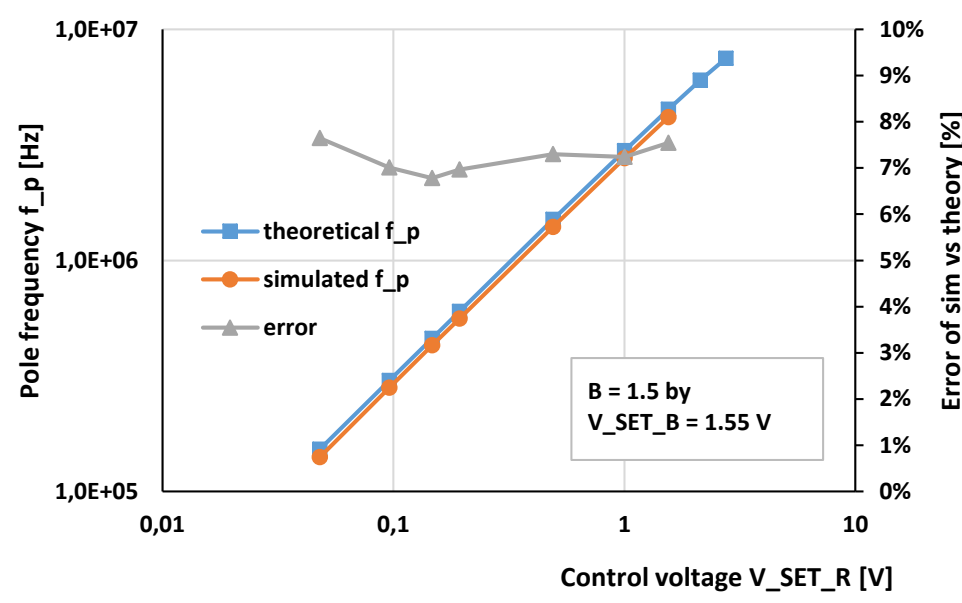

Fig. 7. Tuning suitability analysis under fourth set of conditions showing the possible workability of the filter (tuning of $V_{\mathrm{SET} \_\mathrm{R}}$ while $V_{\text {SET_B }}$ is fixed to high value).

These results lead us to decision that our filter based on the above mentioned models will work properly with the following tuning ranges: $R=\{3060 ; 322\} \Omega$ obtained by $V_{\text {SET_R }}=\{0.147 ; 1.55\} \mathrm{V}$ and $B=\{0.15 ; 1.5\}$ obtained by $V_{\text {SET_B }}=\{0.147 ; 1.55\}$ V. Fig. 8 presents the results of tuning suitability analysis for dual-parameter control, when the above mentioned parameter limits were applied. In order to make the graph better comparable with previous graphs, $\mathrm{X}$ axis represents the product of $V_{\mathrm{SET}_{-} \mathrm{R}}$ and $V_{\mathrm{SET}} \mathrm{B}$.

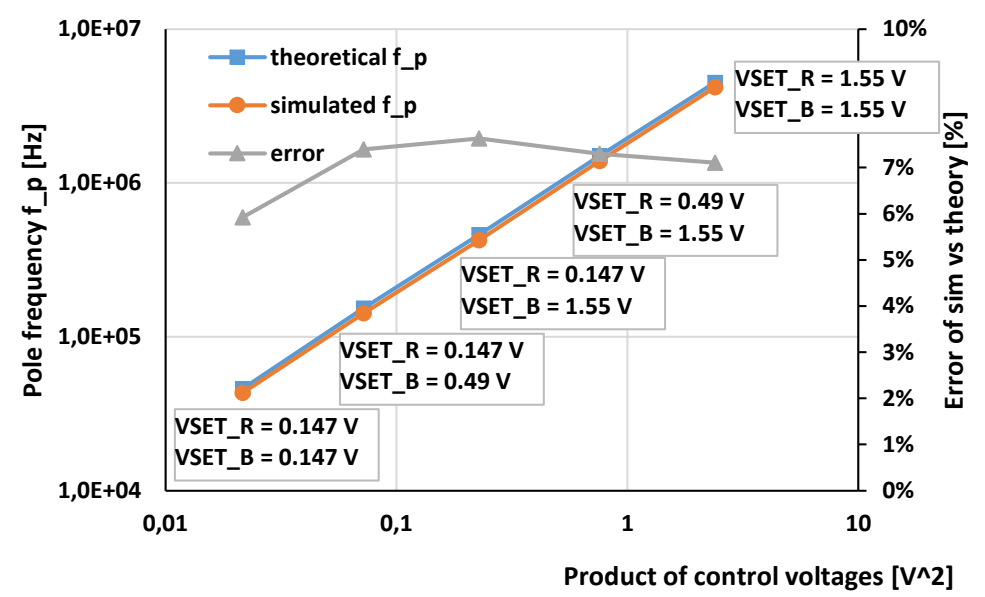

Fig. 8. Dual-parameter tuning suitability analysis showing the possible workability of the filter (tuning of both $V_{\text {SET_R }}$ and $V_{\text {SET_B }}$ ).

In this dual-parameter control scenario, the ratio between the highest and the lowest $f_{\mathrm{P}}$ is 98 in theory, $f_{\mathrm{P}_{-} \mathrm{THEOR}}$ $=\{0.046 ; 4.5\} \mathrm{MHz}$, and it is almost the same in case of the simulation results: it reaches 97 , because tuning range is approximately $f_{\mathrm{P} \_ \text {SIM }}=\{0.043 ; 4.19\} \mathrm{MHz}$. Therefore, it is obvious that dual-parameter control actually extends the tuning range significantly in this particular case (more than 3 times).

Also note that error of simulated $f_{\mathrm{P}}$ against theoretical $f_{\mathrm{P}}$ is not affected by dual-parameter control (it is around $7 \%$ in both the cases). It should be noted that this error is mainly given in all cases by parasitic capacitances that are in parallel to $C_{1}$ and $C_{2}$ and are approximately equal to $10 \mathrm{pF}$. If error caused by parasitic capacitances is neglected or suppressed in simulation by appropriate decrease of working capacitors, all errors are just around 2 $\%$. 


\section{Examples of the Simulation Results with Behavioral Models}

The overall simulation results (prepared in PSpice) of the filter's transfer functions (LP, iBP1, HP, BR) vs theory are depicted in Fig. 9 for these fixed tuning parameters: $B=0.5\left(V_{\mathrm{SET}_{-} \mathrm{B}}=0.49 \mathrm{~V}\right)$ and $R=471 \Omega\left(V_{\mathrm{SET}_{-} \mathrm{R}}\right.$ $=1 \mathrm{~V}$ ). The simulation results match the theory very well except high-frequency band, where the used behavioral model is far beyond its bandwidth [42].

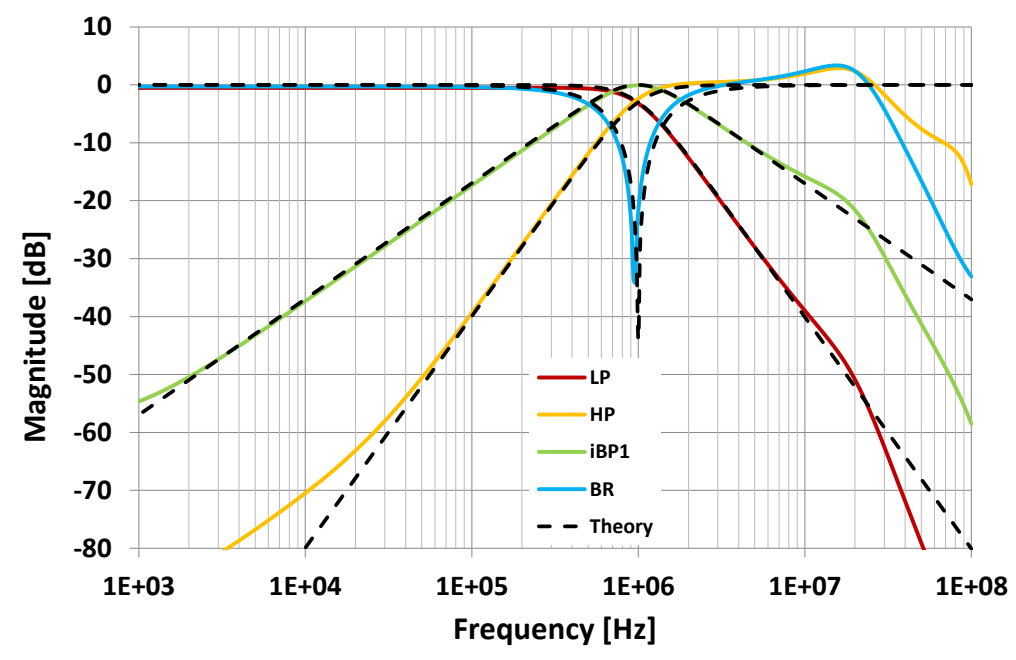

Fig. 9. Overall simulation results of the filter vs theory for $B=0.5\left(V_{\mathrm{SET}_{-} \mathrm{B}}=0.49 \mathrm{~V}\right)$ and $R=471 \Omega\left(V_{\mathrm{SET}_{-} \mathrm{R}}=1 \mathrm{~V}\right)-$ with behavioral models.

Dual-parameter control of $f_{\mathrm{P}}$ in the case of LP and AP transfer function is shown in Fig. 10 and Fig. 11. The first figure shows the magnitude response of LP, second phase response of AP, as an example. From both graphs it is obvious that ratio between the highest and the lowest $f_{\mathrm{P}}$ in simulation and theory is similar and around 100 and both tuning parameters respect above derived limits (Fig. 8 and related text).

The last graph (Fig. 12) shows the possibility of tuning the pass-band gain in the case of iBP2 function (by $B_{21}$ controlled by $\left.V_{\mathrm{SET}_{-} \mathrm{B} 21}\right)$ while the first and second tuning parameters were fixed to: $B=0.5\left(V_{\mathrm{SET} \_\mathrm{B}}=0.49 \mathrm{~V}\right)$ and $R=471 \Omega\left(V_{\mathrm{SET}_{-} \mathrm{R}}=1 \mathrm{~V}\right)$. Control voltage $V_{\mathrm{SET}_{-} \mathrm{B} 21}$ was tuned from $0.1 \mathrm{~V}$ up to $4 \mathrm{~V}$ in this particular case in order to prove both the attenuation and amplification in the pass band of the iBP2 function.

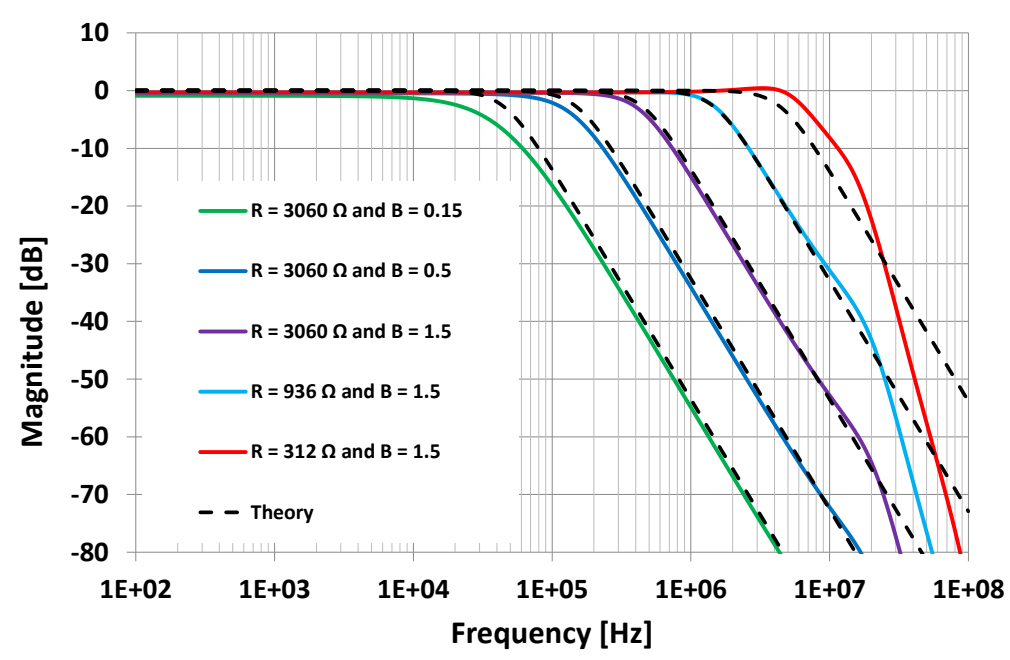

Fig. 10. Dual-parameter tuning of $f_{\mathrm{P}}$ of the LP function (magnitude response) - with behavioral models. 


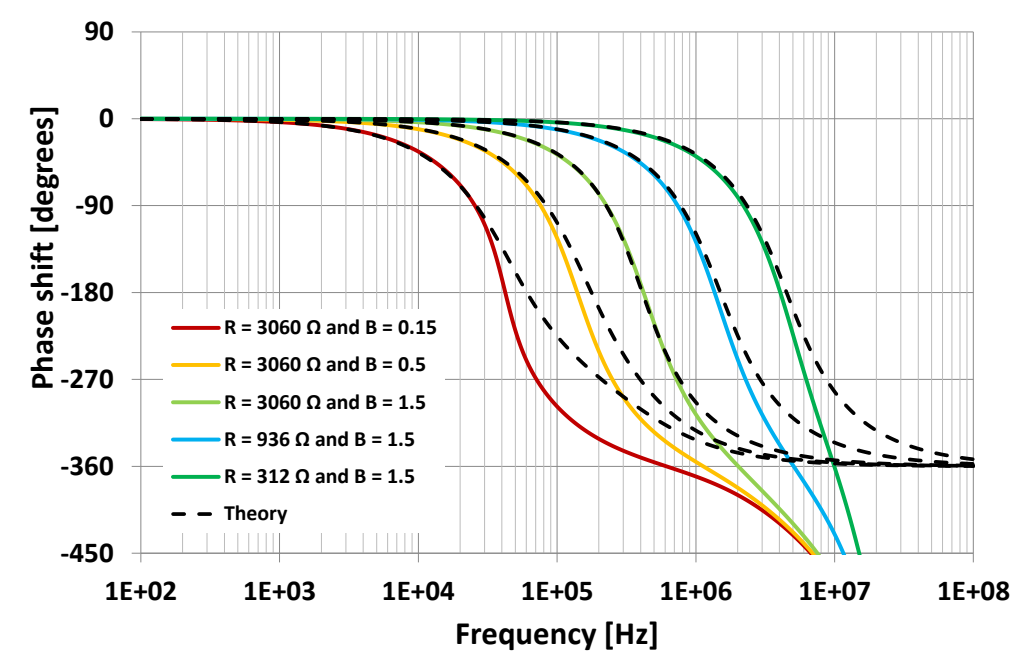

Fig. 11. Dual-parameter tuning of $f_{\mathrm{P}}$ of the AP function (phase response) - with behavioral models.

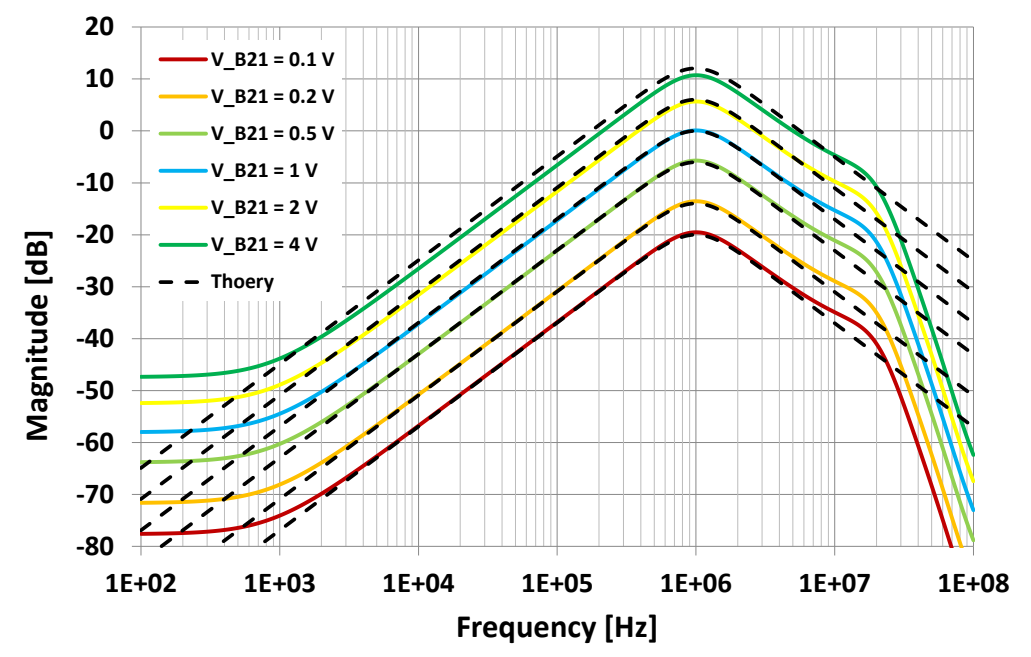

Fig. 12. Control of pass-band gain of the iBP2 function (magnitude response) by $V_{\text {SET_B21 }}-$ with behavioral models.

\section{Measurement Results with Prototype using Behavioral Representation of Active Elements}

Filtering structure shown in Fig. 3 was not only simulated in Pspice simulator, but also measured in lab environment. As mentioned above, there is no MCDU element on the market but it is possible to implement it by behavioral model using available active devices in order to prove the workability of the concept. Particular configuration of MCDU model used in this setup is shown in Fig. 13. Note that two MCDUs together with one UCC (Fig. 2) and two grounded capacitors are required for implementation of our filter. The measurement results, obtained with help of Agilent 4395A network analyzer, are presented under the similar conditions as simulation results in the previous section in order to be mutually comparable.

The first graph (Fig. 14) presents overall filter performance vs simulation results. Unfortunately, there are some additional limitations of behavioral model of MCDU and also of complexity of printed-circuit board (PCB). Therefore, high frequency response is not following theoretical expectations very well. It is also obvious that pole frequency is significantly lower $(711 \mathrm{kHz}$ in case of BR response vs $955 \mathrm{kHz}$ in simulations). It is 
caused by the combination of the following effects: 1) additional parasitic nodal capacitances having value around $10 \mathrm{pF}$ summed with working capacitors, 2) measurement of real prototype of MCDU proved that real current gains ( $B_{11}$ and $B_{22}$ especially) have lower real values in this particular configuration than expected from simulations (around 10\% error) [41], 3) slightly higher values of controlled input resistances than expected from simulation (also around 10\% error) [41]. However, it should be noted that the obtained results are sufficient for verification of the concept and of tuning capabilities as presented in Fig. 15 and 16.

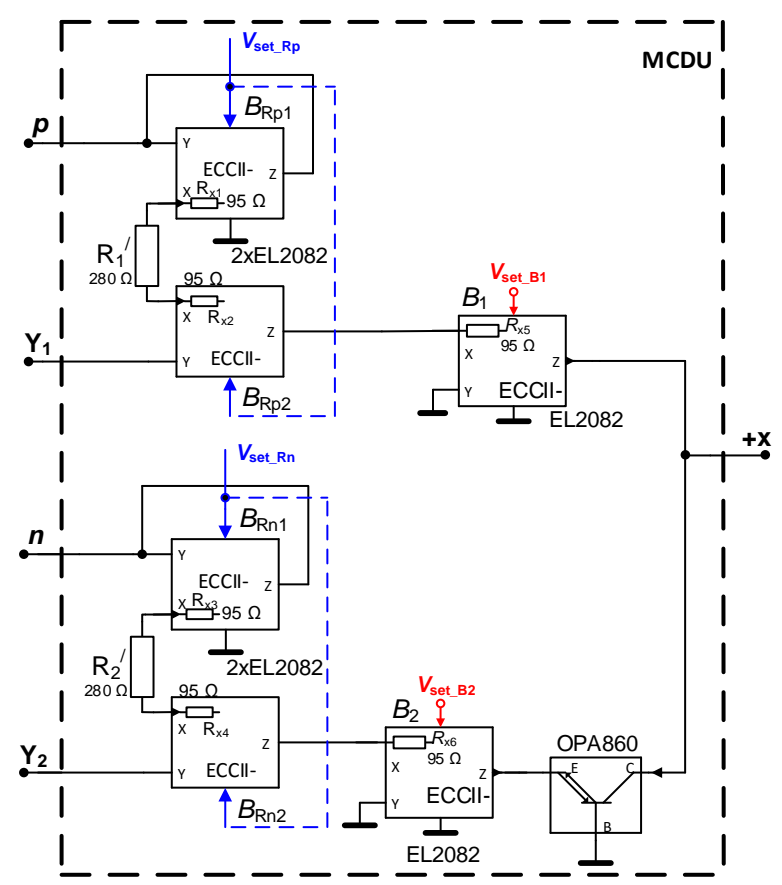

Fig. 13. Particular behavioral implementation of MCDU active element used for experimental verification of filter from Fig. 3 [40].

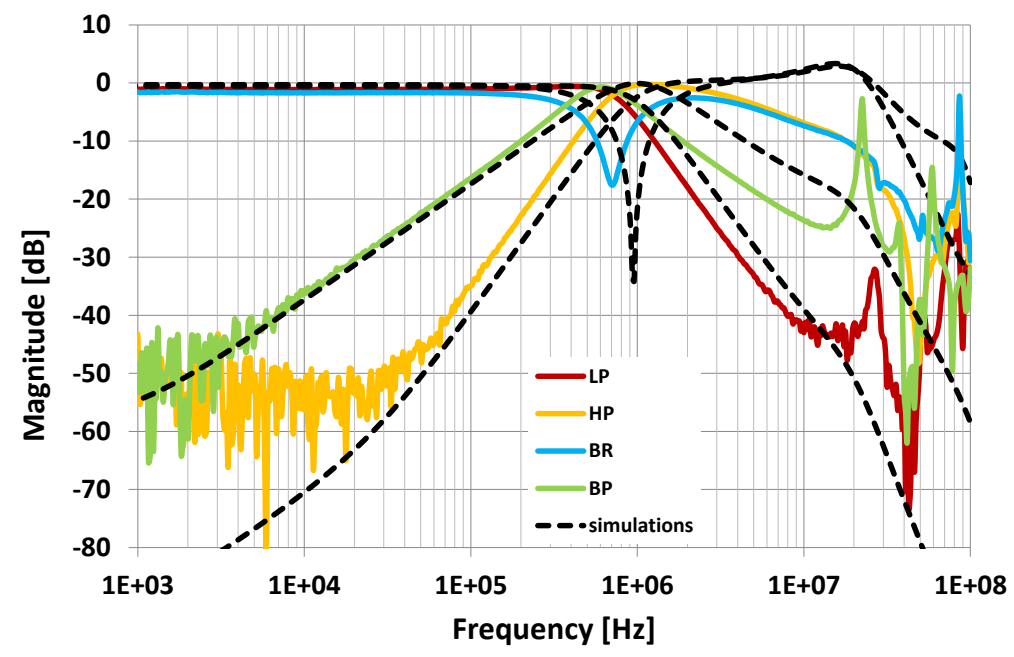

Fig. 14. Overall measurement results of the filter vs. simulation results for the following setup: $V_{\mathrm{SET}_{-} \mathrm{B}}=0.49 \mathrm{~V}$ and $V_{\mathrm{SET} \_\mathrm{R}}=1 \mathrm{~V}$ (magnitude responses) - with behavioral models. 


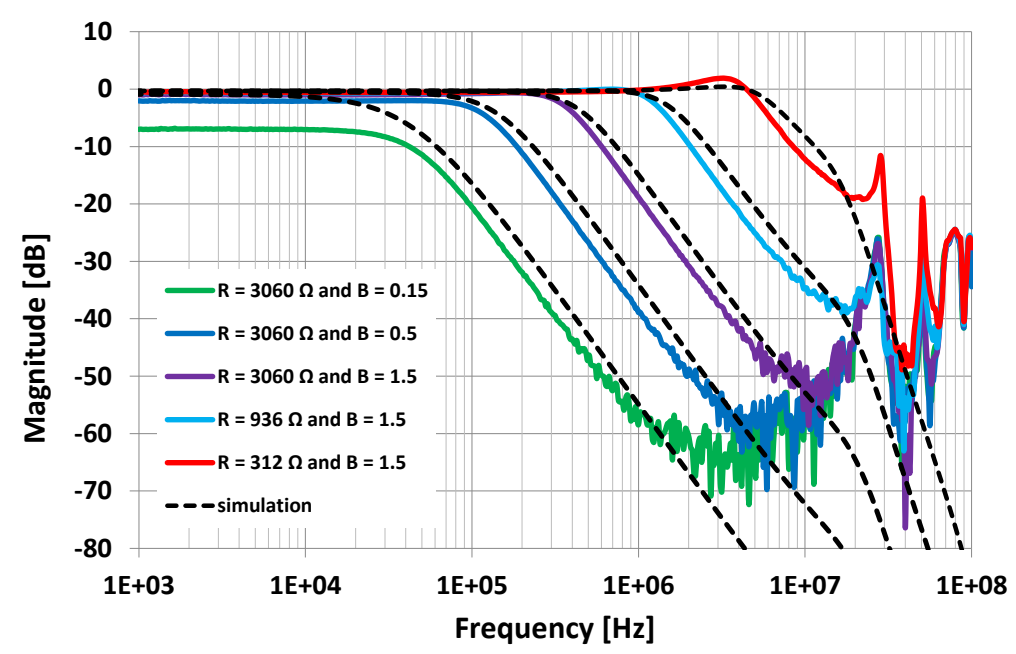

Fig. 15. Measurement results of dual-parameter tuning of $f_{\mathrm{P}}$ in the case of the LP function (magnitude responses) - with behavioral models.

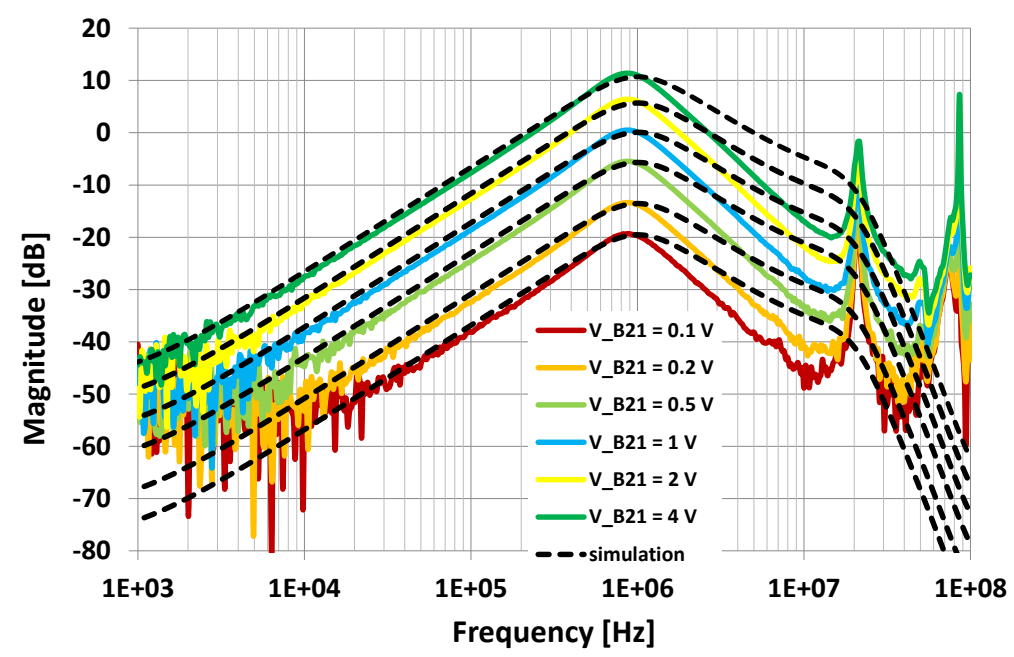

Fig. 16. Measurement results for control of pass-band gain of the iBP2 function (magnitude response) by $V_{\mathrm{SET} \_\mathrm{B} 21}-$ with behavioral models.

When compared to the simulation results, pass-band gain of the LP response is slightly dependent on particular setting of the pole frequency (Fig. 15), but it is not worse than $-1.5 \mathrm{~dB}$ for most of the tuning range. It is caused mainly by non-ideal (i.e. lower) current gains in branches of the circuit leading to additional terms of $\boldsymbol{s}^{0}$ in (8). Obtained real pole frequencies are: 42, 126, 400, 1371 and $5640 \mathrm{kHz}$, i.e. ratio between the highest and lowest $f_{\mathrm{p}}$ is over 100 also in case of measurement.

The last graph of this section (Fig. 16) shows the possibility of tuning the pass-band gain in the case of iBP2 function (by $B_{21}$ controlled by $V_{\text {SET_B21 }}$ ) while first and second tuning parameters were fixed to the same values as in the case of simulations: $V_{\text {SET_B }}=0.49 \mathrm{~V}$ and $V_{\text {SET_R }}=1 \mathrm{~V}$. Control voltage $V_{\text {SET_B21 }}$ was tuned from $0.1 \mathrm{~V}$ up to $4 \mathrm{~V}$. The obtained values of attenuation or amplification in the pass band are in very good agreement with theory in this particular case.

\section{Implementation of active elements on transistor level}

After successful verification of workability of concept with behavioral model (by simulations and also by measurement), both MCDU and MO-CF were designed on transistor level with I3T $0.35 \mu \mathrm{m}$ ON Semi 
technology models. This step should prove that possible on-chip integration should improve the obtained results in useful frequency band.

MCDU was built from 4 blocks, having two paths connected on the output, as obvious from Fig. 17. Abbreviation CCCII stands for Current-Controlled Current Conveyor of second generation [41] and ACA stands for Adjustable Current Amplifier [16]. Four DC currents are available for control of four tunable parameters of MCDU ( $B_{1}$ is current gain in positive path, $B_{2}$ is current gain in negative path, $R_{\mathrm{p}}$ is intrinsic resistance of $p$ input and $R_{\mathrm{n}}$ is intrinsic resistance of $n$ input. Note that which input terminal is $p$ (and $\mathrm{Y}_{1}$ ) and which is $n\left(\right.$ and $\left.\mathrm{Y}_{2}\right)$ is given by used output of ACA, because both channel are exactly the same.

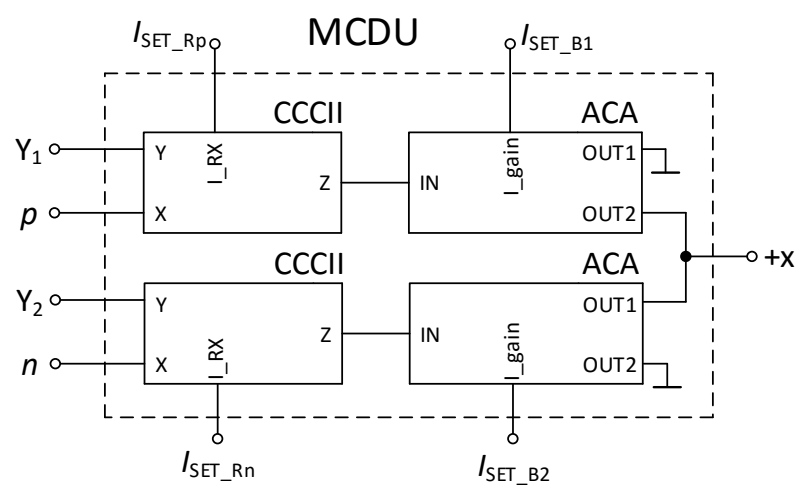

Fig. 17. Block diagram of transistor-level implementation of MCDU element.

Designed transistor-level structure of CCCII and ACA blocks of MCDU active element are shown in Fig. 18 and Fig. 19 respectively. All transistor dimensions and also DC currents of auxiliary current sources are included in figures, supply voltage had standard values: $\mathrm{V}_{\mathrm{DD}}=-\mathrm{V}_{\mathrm{SS}}=1.65 \mathrm{~V}$.

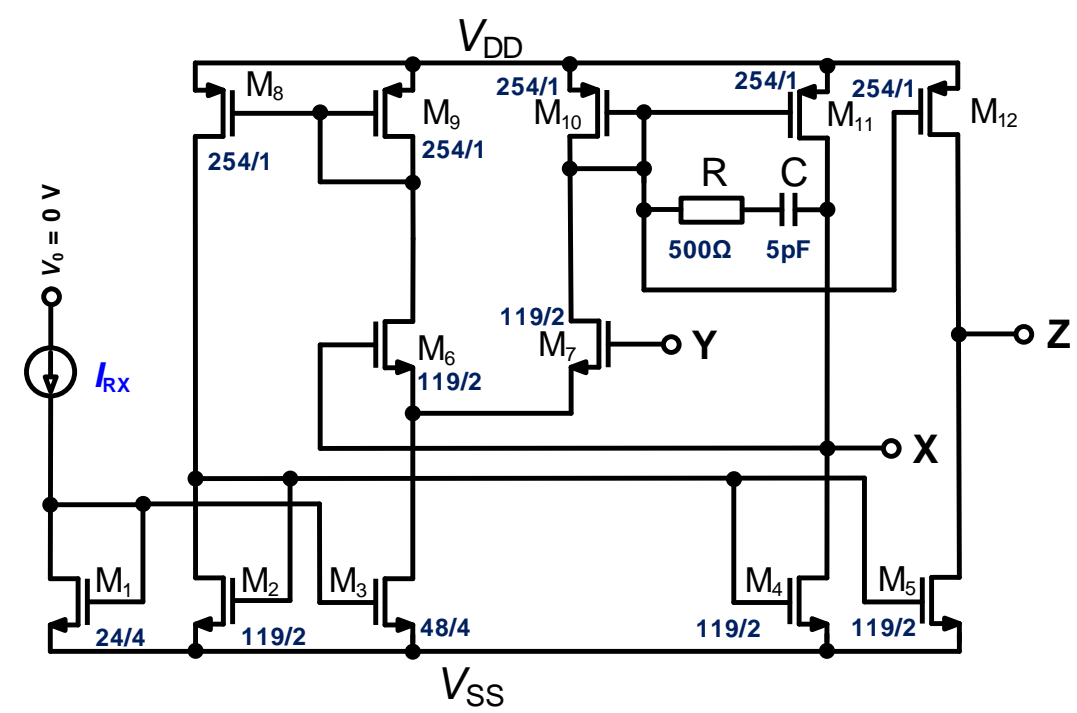

Fig. 18. Designed transistor-level implementation of CCCII block (part of MCDU element). 


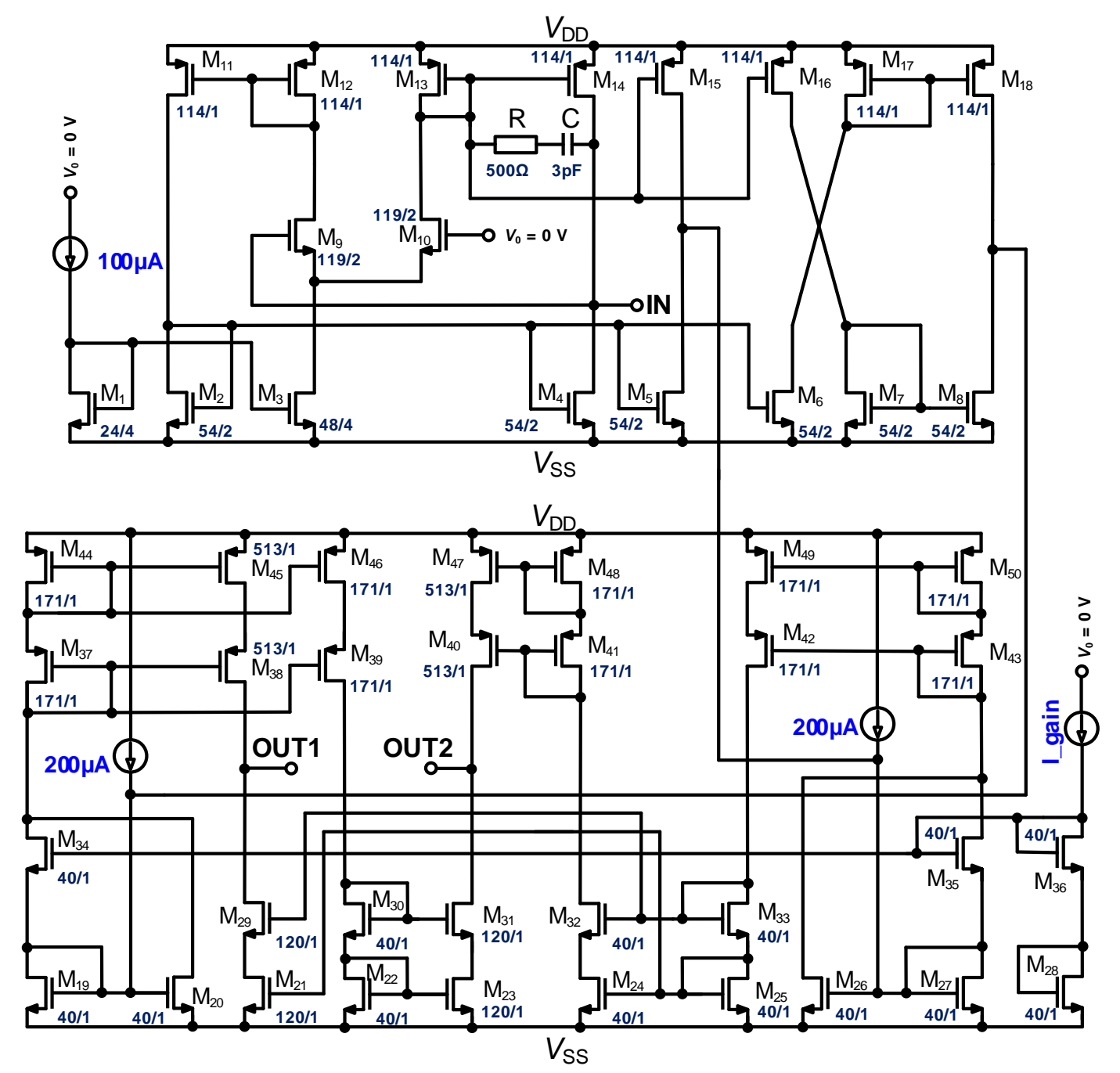

Fig. 19. Designed transistor-level implementation of ACA block (part of MCDU element).

Table 2: The most significant parameters of MCDU transistor-level implementation

\begin{tabular}{|c|c|c|}
\hline Parameter(s) & Obtained value or range of values & 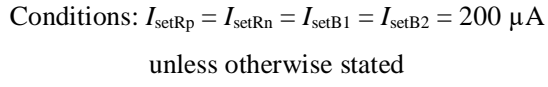 \\
\hline current gain $I_{+\mathrm{x}} / I_{\mathrm{p}}[-]$ & $0.15-5.92(\mathrm{BW}=52-30 \mathrm{MHz})$ & $I_{\mathrm{setB} 1}=271-16 \mu \mathrm{A}, I_{\mathrm{setB} 2}=0 \mu \mathrm{A}$ \\
\hline current gain $I_{+\mathrm{x}} / I_{\mathrm{n}}[-]$ & $0.15-5.95(\mathrm{BW}=68-48 \mathrm{MHz})$ & $I_{\mathrm{setB} 1}=271-16 \mu \mathrm{A}, I_{\mathrm{setB} 1}=0 \mu \mathrm{A}$ \\
\hline intrinsic resistance $V_{\mathrm{p}} / I_{\mathrm{p}}, V_{\mathrm{n}} / I_{\mathrm{n}}[\mathrm{k} \Omega]$ & $0.31-3.07$ & $I_{\mathrm{setRp}}=I_{\mathrm{setRn}}=700-16 \mu \mathrm{A}$ \\
\hline$+\mathrm{x}$ output resistance $[\mathrm{M} \Omega]$ & $0.63-1.16$ & $I_{\mathrm{setB} 1}=I_{\mathrm{setB} 2}=271-16 \mu \mathrm{A}$ \\
\hline$+\mathrm{x}$ output capacitance $[\mathrm{pF}]$ & 2.6 & - \\
\hline voltage transfer from Y1 to $\mathrm{p}[-]$ & 0.99 & $I_{\mathrm{p}}=0 \mu \mathrm{A}$ \\
\hline voltage transfer from Y2 to $\mathrm{n}[-]$ & 0.99 & $I_{\mathrm{n}}=0 \mu \mathrm{A}$ \\
\hline typical $+\mathrm{x}$ output dynamic range $[\mu \mathrm{A}]$ & \pm 200 & - \\
\hline $\mathrm{Y} 1, \mathrm{Y} 2$ input resistance and capacitance $[\mathrm{G} \Omega \| \mathrm{pF}]$ & $3 \| 0.5$ & - \\
\hline
\end{tabular}


Table 3: The most significant parameters of MO-CF transistor-level implementation built from CCCII structure shown in Fig. 18

\begin{tabular}{|c|c|}
\hline Parameter(s) & $\begin{array}{c}\text { Obtained value or range of values for } I_{\mathrm{RX}} \\
=100 \mu \mathrm{A} \text { (bias current) }\end{array}$ \\
\hline current gain Iz1- / Ix, Izz- / Ix [-] & $1.00(\mathrm{BW}=55 \mathrm{MHz})$ \\
\hline current gain $I_{\mathrm{Z} 1+} / I_{\mathrm{X}}[-]$ & $0.99(\mathrm{BW}=68 \mathrm{MHz})$ \\
\hline intrinsic resistance $V_{\mathrm{X}} / I_{\mathrm{x}}[\mathrm{k} \Omega]$ & 0.78 \\
\hline $\mathrm{Z} 1+$ output resistance $[\mathrm{k} \Omega]$ & 151 \\
\hline Z1+ output capacitance $[\mathrm{pF}]$ & 0.5 \\
\hline output Z1-, Z2- resistance [k $\Omega]$ & 149 \\
\hline Z1-, Z2- output capacitance [pF] & 0.6 \\
\hline typical Z1+, Z1-, Z2- output dynamic range $[\mu \mathrm{A}]$ & \pm 200 \\
\hline
\end{tabular}

Note that MO-CF active element was easily obtained from the structure of CCCII (Fig. 17) - input $\mathrm{Y}$ has to be grounded and a required number of outputs can be obtained easily by copying/inverting of output current. Value of $I_{\mathrm{RX}}$ (refer to Fig. 18) was fixed to $100 \mu \mathrm{A}$ in this particular case, supply voltage was $\mathrm{V}_{\mathrm{DD}}=-\mathrm{V}_{\mathrm{SS}}=1.65$ V.

The parameters of both designed active elements (MCDU, MO-CF) are summarized in Table 2 and Table 3. It is obvious that tuning ranges are purposely similar (or wider) to ranges obtained in the case of behavioral model presented in the previous sections.

\section{Simulation Results of the Designed Filter with Transistor-level Models}

Prepared transistor-level implementations of active elements were used in simulations of the filter's transfer functions in order to prove the workability of models in this particular scenario. The following transfer functions are compared vs theoretical expectations in Fig. 20: LP, iBP1, HP, BR for these fixed tuning parameters: $B=0.5$ $\left(I_{\text {SET_B }}=228 \mu \mathrm{A}\right)$ and $R=471 \Omega\left(I_{\text {SET_R }_{-}}=242 \mu \mathrm{A}\right)$. The simulation results match the theory very well except HP and $\mathrm{BR}$ response at high-frequency band above $30 \mathrm{MHz}$ as expected when considering parameters from Table 1 and Table 2. Pole frequency is $977 \mathrm{kHz}$ in case of BR response - when compared with $955 \mathrm{kHz}$ obtained in simulation with behavioral models, it is closer to theoretical expectation $\left(f_{\mathrm{p}_{-} \text {theor }}=1 \mathrm{MHz}\right)$.

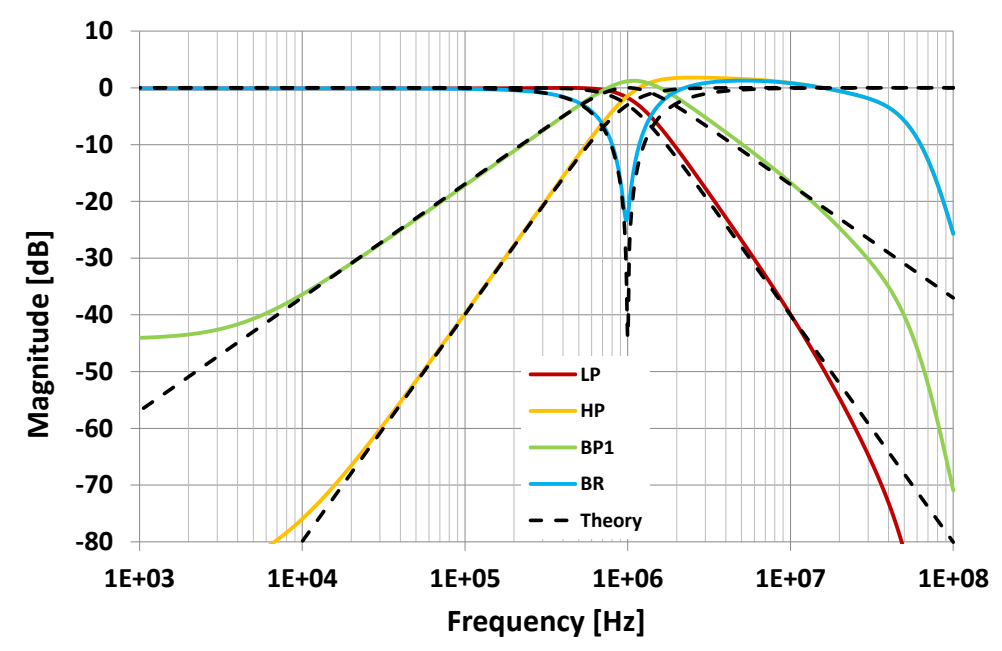


Fig. 20. Overall simulation results of the filter vs theory for $B=0.5\left(I_{\mathrm{SET} \_\mathrm{B}}=228 \mu \mathrm{A}\right)$ and $R=471 \Omega\left(I_{\mathrm{SET} \_\mathrm{R}}=242 \mu \mathrm{A}\right)-$ with transistor-level models.

Dual-parameter control of $f_{\mathrm{P}}$ in the case of LP (magnitude response) and AP (phase response) transfer functions are shown in Fig. 21 and Fig. 22, similarly to Fig. 10 and Fig. 11. LP response low-frequency passband gain is in range from -1 to $0 \mathrm{~dB}$ for each of the cases, which is considered as a very good result. When compared with Fig. 10, response with the lowest and the highest pole frequency proved better matching with theory. From both graphs (Fig. 21 and 22) it is obvious that ratio between the highest and the lowest $f_{\mathrm{P}}$ is above 100. Values of resistors $(R)$ and current gain $(B)$ mentioned in graphs were obtained by the following values of control currents: $R=3060 \Omega\left(I_{\text {SET_R }}=16 \mu \mathrm{A}\right), R=936 \Omega\left(I_{\text {SET_R }_{-}}=76 \mu \mathrm{A}\right), R=312 \Omega\left(I_{\text {SET_R }}=700 \mu \mathrm{A}\right), B=$ $0.15\left(I_{\text {SET_B }}=271 \mu \mathrm{A}\right), B=0.5\left(I_{\text {SET_B }_{-}}=228 \mu \mathrm{A}\right)$ and $B=1.5\left(I_{\text {SET_B }}=170 \mu \mathrm{A}\right)$.

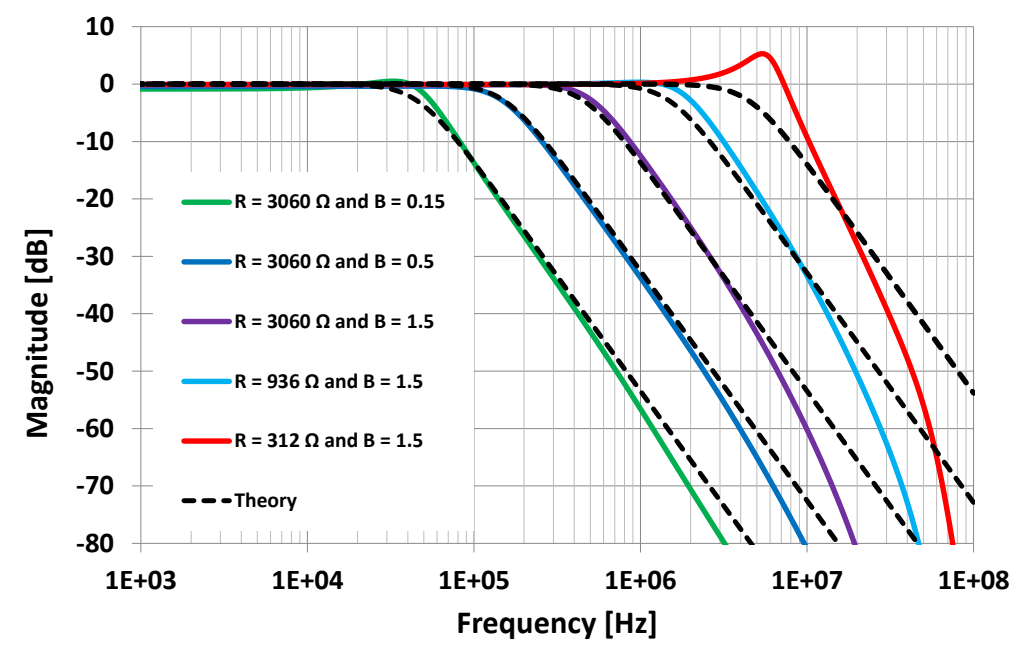

Fig. 21. Dual-parameter tuning of $f_{\mathrm{P}}$ of the LP function (magnitude response) - with transistor-level models.

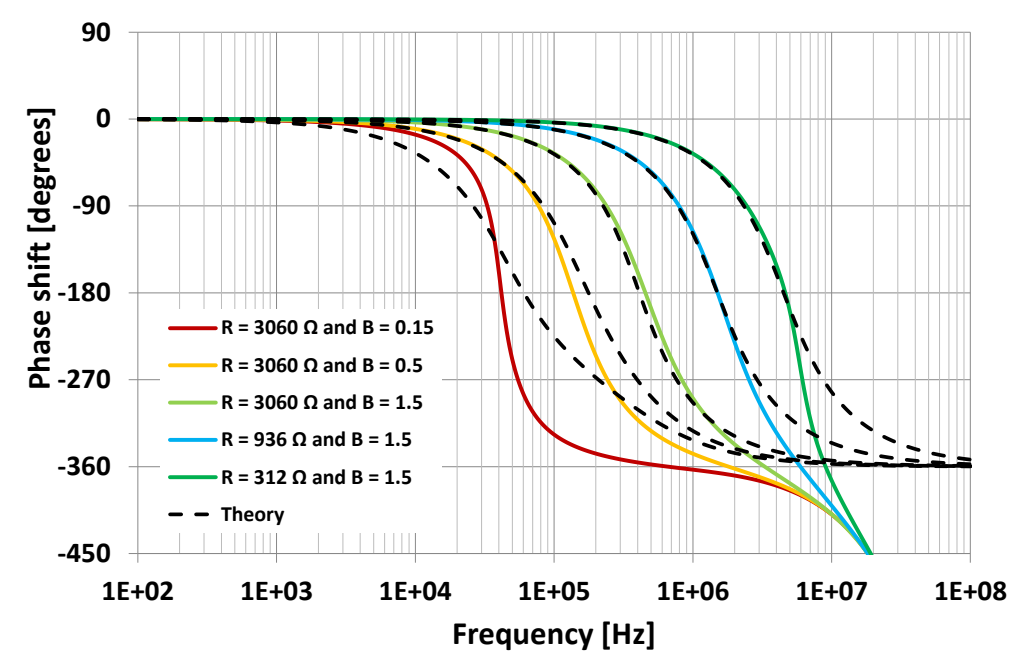

Fig. 22. Dual-parameter tuning of $f_{\mathrm{P}}$ of the AP function (phase response) - with transistor-level models. 


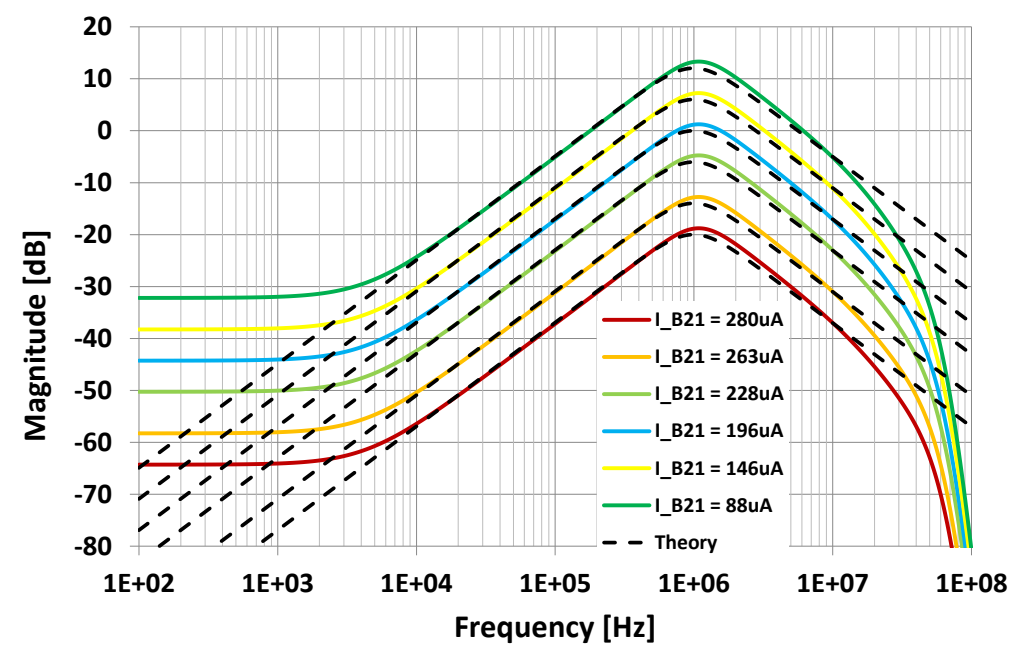

Fig. 23. Control of pass-band gain of the iBP2 function (magnitude response) by $I_{\mathrm{SET}_{-} \mathrm{B} 21}-$ with transistor-level models.

The last graph (Fig. 23) shows the possibility of tuning the pass-band gain in the case of iBP2 function (by $B_{21}$ controlled by $I_{\text {SET_B21 }}$ ) while other tuning parameters were fixed to the same values as in the case of Fig. 20 . The simulation results match the theory very well, there is only problem with limited attenuation in low-frequency stop band that is moreover dependent on tuning process. This issue is caused by relative low output impedance of MO-CF as obvious from topology in Fig. 3 and parameters shown in Table 3. It could be improved, but as the result, the dynamic range and/or bandwidth of the active element will be decreased. We consider the obtained results as sufficient when gain $B_{21}<2$, which is sufficient for many applications. The attenuation is above $40 \mathrm{~dB}$ in these cases.

\section{Conclusions}

This paper presented dual-parameter control of universal current-mode filter. Tuning suitability analyses help us to determine optimal tuning range of the individual parameters. The simulation results with behavioral models proved that dual-parameter type of control of the filter's parameters is very useful and extends the tuning range. In our case the ratio between the highest and the lowest $f_{\mathrm{P}}$ was around 100 (two decades) both in simulation and theory. It is 3 times wider range than in the case of single-parameter control and moreover it is a very good result in comparison with already published works summarized in Table 1. Moreover, these simulation results were confirmed by lab measurement. Although there are some limits of complex system of PCB and also converters from voltage to current and from current to voltage required for real measurement, so as limited bandwidth and non-ideal parameters of active elements apply, we consider the obtained results as satisfactory and as a stimulus to perform CMOS design of both active elements required to simulate whole filtering structure and to compare all obtained responses with theory. Matching of simulation results with transistor-level models vs theory is much better in the case of these precisely designed CMOS models. Power consumption of MCDU and MO-CF elements (that are not designed to be low-power devices) depends on particular values of control current and varies from $24 \mathrm{~mW}$ to $66 \mathrm{~mW}$ in case of MCDU and is fixed to $3.4 \mathrm{~mW}$ in case of MO-CF. 


\section{Acknowledgement}

Research described in this paper was financed by the National Sustainability Program under grant LO1401 and by the Czech Science Foundation under grant no. GJ16-11460Y. For the research, infrastructure of the SIX Center was used.

Authors would also like to thank Editor for choosing this paper for this Special Issue. Authors also wish to thank the anonymous reviewers for their useful and constructive comments that helped to improve the paper in all stages of paper preparation.

A preliminary version of this paper has been presented at the 9th International Conference on Electrical and Electronics Engineering - ELECO 2015 [42].

\section{References}

[1] Chen, W. K. (2009). The Circuits and Filters Handbook. New York: Third Edition CRC Press.

[2] Kumngern, M., Khateb, F., Dejhan, K., Phasukkit, P., \& Tungjitkusolmun, S. (2013). Voltage-Mode Multifunction Biquadratic Filters Using New Ultra-Low-Power Differential Difference Current Conveyors. Radioengineering, 22(2), 448-457.

[3] Kacar, F., Metin, B., Kuntman, H., \& Cicekoglu, O. (2009). Current-Mode Multifunction Filters Using a Single FDCCII. In Int. Conf. on Electrical and Electronics Engineering (ELECO) 2009 (pp. II/54 - II/57).

[4] Wang, H. Y., \& Lee, C. T. (2001). Versatile insensitive current-mode universal biquad implementation using current conveyors. IEEE Transaction on Circuits and Systems II: Analog and Digital Signal Processing, 48(4), 409-413.

[5] Sun, Y., Fidler, J. K. (1996). Structure generation of current-mode two integrator loop dual output-OTA grounded capacitor filters. IEEE Transaction on Circuits and Systems II: Analog and Digital Signal Processing, 43(9), 659-663.

[6] Yuce, E. (2009). Voltage-Mode Multifunction Filters Employing a Single DVCC and Grounded Capacitors. IEEE Transaction on Instrumentation and Measurement, 58(7), 2216-2221.

[7] Ray, B. N. (2004). Synthesis of programmable multi-input current-mode linear analog circuits. IEEE Transaction on Circuits and Systems I: Regular papers, 51(8), 1440-1456.

[8] Jerabek, J., \& Vrba, K. (2010). SIMO type low-input and high-output impedance current- mode universal filter employing three universal current conveyors. AEU - International Journal of Electronics and Communications, 64(6), 588-593.

[9] Jaikla, W., Siripongdee, S., \& Suwanjan, P. (2012). MISO Current-mode Biquad Filter with Independent Control of Pole Frequency and Quality Factor. Radioengineering, 21(3), 886-891.

[10] Uygur, A., Kuntman, H., \& Zeki, A. (2005). Multi-input Multi-output CDTA-based KHN filter. In Int. Conf. on Electrical and Electronics Engineering (ELECO) 2005 (pp. 46-50).

[11] Alpaslan, H., \& Yuce, E. (2012). Current-mode Biquadratic Universal Filter Design with Two Terminal Unity Gain Cells. Radioengineering, 21(1), 304-311.

[12] Minaei, S., Sayin, O. K., \& Kuntman, H. (2006). A New CMOS Electronically Tunable Current Conveyor and Its Application to Current-Mode Filters. IEEE Transactions on Circuits and Systems-Part-I: Regular Papers, 53(7), 1448-1457. 
[13] Naglich, E. J., Lee, J., Peroulis, D., \& Chappell, W. J. (2012). Extended Passband Bandstop Filter Cascade with Continuous 0.85 to $6.6 \mathrm{GHz}$ Coverage. IEEE Trans. Microwave Theory and Techniques, 60(1), 21-30.

[14] Adoum, B. A., \& Wen, W. P. (2012). Investigation of Band-Stop to All Pass Reconfigurable Filter. In 4th Int. Conf. on Intelligent and Advanced Systems (pp. 190-193).

[15] Minaei, S., Yuce, E., \& Cicekoglu, O. (2005). Electronically Tunable Multi-Input Single-Output VoltageMode Filter. In 2005 European Conference on Circuit Theory and Design (pp. III/401-III/404).

[16] Jerabek, J., Koton, J., Sotner, R., \& Vrba, K. (2013). Adjustable band-pass filter with current active elements: two fully-differential and single-ended solutions. Analog Integrated Circuits and Signal Processing, 74(1), 129-139.

[17] Siripruchyanun, M., \& Jaikla, W. (2008). Current controlled current conveyor transconductance amplifier (CCCCTA): a building block for analog signal processing. Electrical Engineering, 90(6), 443-453.

[18] Keskin, A. U., Biolek, D., Hancioglu, E., \& Biolkova, V. (2006). Current-mode KHN filter employing current differencing transconductance amplifiers. AEU - International Journal of Electronics and Communications, 60(6), 443-446.

[19] Herencsar, N., Koton, J., Vrba, K., \& Lahiri, A. (2009). New voltage-mode quadrature oscillator employing single DBTA and only grounded passive elements. IEICE Electronics Express, 6(24), 1708-1714.

[20] Sotner, R., Herencsar, N., Jerabek, J., Prokop, R., Kartci, A., Dostal, T., \& Vrba, K. (2014). Z-Copy Controlled-Gain Voltage Differencing Current Conveyor: Advanced Possibilities in Direct Electronic Control of First-Order Filter. Elektronika Ir Elektrotechnika, 20(6), 77-83.

[21] Soulitis, G., \& Psychalinos, C. (2009). Electronically controlled multiphase sinusoidal oscillators using current amplifiers. International Journal of Circuit Theory and Applications, 37(1), 43-52.

[22] Herencsar, N., Jerabek, J., Koton, J., Vrba, K., Minaei, S., \& Göknar, C. (2015). Pole frequency and passband gain tunable novel fully-differential current-mode all-pass filter. In 2015 IEEE International Symposium on Circuits and Systems (ISCAS) (pp. 2668-2671).

[23] Jerabek, J., Sotner, R., Herencsar, N., Jaikla, W., \& Vrba, K. (2015). Behavioral Model for Z-copy Voltage Controlled Current Follower Differential Input Transconductance Amplifier and Its Features. In 2015 38th International Conference on Telecommunications and Signal Processing (pp. 703-707).

[24] Chen, H. P., \& Chu P. L. (2009). Versatile universal electronically tunable current-mode filter using CCCIIs. IEICE Electronics Express, 6(2), 122-128.

[25] Singh, S. V., Maheshwari, S., \& Chauhan, D. S. (2010). Universal Current-Controlled Current-Mode Biquad Filter Employing MO-CCCCTAs and Grounded Capacitors. Circuits and Systems, 1(2), 35-40.

[26] Chaichana, A., Jantakun, A., Kumngern, M., \& Jaikla, W. (2015). Current-mode MISO filter using CCCDTAs and grounded capacitors. Indian Journal of Pure and Applied Physics, 53(6), 470-477.

[27] Kumngern, M., Khateb, F., Phasukkit, P., Tungjitkusolmun, S., \& Junnapiya, S. (2014). ECCCII-based current-mode universal filter with orthogonal control of w0 and Q. Radioengineering, 23(2), 687-696.

[28] Walde, N., \& Ahmad, S. N. (2015). Realization of a New Current Mode Second-Order Biquad Using Two Current Follower Transconductance Amplifiers (CFTAs). Circuits and Systems, 6(5), 113-120.

[29] Srisakultiev, S., Lawanwisut, S., \& Siripruchyanun, M. (2013). A current-mode electronically controllable multifunctional biquadratic filter using CCCIIs. International Journal of Advances in Telecommunications, Electrotechnics, Signals and Systems, 2(2), 45-50. 
[30] Singh, S. V., Maheshwari, S., \& Chauhan, D. S. (2010). Elecronically tunable current-mode SIMO/MISO universal biquad filter using MO-CCCCTAs. Int. Journal on Electrical and Power Engineering (ACEE), $1(3), 36-41$.

[31] Sotner, R., Slezak, J., Dostal, T., \& Petrzela, J. (2010). Universal tunable current-mode biquad employing distributed feedback structure with MO-CCCII. Journal of Electrical Engineering, 61(1), 52-56.

[32] Sotner, R., Slezak, J., \& Petrzela, J. (2009). Current Mode Tunable KHN Filter Based on Controlled MOCFTAs. In 3rd International Conference on Signals, Circuits and Systems SCS2009 (pp. 521-524).

[33] Suwanjan, P., \& Jaikla, W. (2012). CFTA MISO Current-mode biquad filter. Recent Researches in Circuits, Systems, Multimedia and Automatic Control, 93-97.

[34] Koomchaya, A., Suvanjan, P., Jaikla, A., \& Maneewan, S. (2012). A MISO Current-mode Biquad Filter Using a Minimum Number of Active and Passive Components. In IEEE International Conference on Electron Devices and Solid State Circuit (EDSSC) (pp. 1-4).

[35] Kumngern, M. (2012). Electronically Tunable Current-Mode Universal Biquadratic Filter using a Signle CCCFTA. In IEEE International Symposium on Circuits and Systems (ISCAS) (pp. 1175-1178).

[36] Sotner, R., Slezak, J., \& Dostal T. (2010). Influence of Mirroring of Current Output Responses through Grounded Passive Elements. In Proceedings of the 20th International Conference Radioelektronika (pp. 177-180).

[37] Jerabek, J., Sotner, R., Kincl, Z., Dostal, T., \& Vrba K. (2013). Study of Practical Problems in Two-Loop CCTA Based Biquad: Finite Attenuations in Stop Bands. In 8th International Conference on Electrical and Electronics Engineering (pp. 40-44).

[38] Sotner, R., Petrzela, J., Jerabek, J., \& Dostal T. (2015). Reconnection-less OTA- based Biquad Filter with Electronically Reconfigurable Transfers. Elektronika Ir Elektrotechnika, 21(3), 33-37.

[39] Sotner, R., Jerabek, J., Herencsar, N., \& Vrba, K. (2015). Design of the simple oscillator with linear tuning and pi/4 phase shift based on emulator of the modified current differencing unit. IEICE Electronics Express, 12(19), 1-7.

[40] Sotner, R., Jerabek, J., Herencsar, N., Zak, T., Jaikla, W., \& Vrba, K. (2015). Modified Current Differencing Unit and its Application for Electronically Reconfigurable Simple First-order Transfer Function. Advances in Electrical and Computer Engineering, 15(1), 3-10.

[41] Polak, J., Jerabek, J., Langhammer, L., \& Sotner, R. (2015). Practical AC \& DC measurements of new MCDU active element. Elektrorevue, 6(1), 25-29.

[42] Jerabek, J., Sotner, R., Herencsar, N., Polak, J., Dvorak, J., \& Koton, J. (2015). MISO Universal Frequency Filter with Dual-Parameter Control of the Pole Frequency. In 9th Int. Conf. on Electrical and Electronics Engineering (ELECO) (pp. 101-105). 